\title{
EL CONCEPTO PEDAGÓGICO 'FORMACIÓN’ EN EL UNIVERSO SEMÁNTICO DE LA EDUCACIÓN
}

\author{
María Eugenia Venegas Renauld \\ Directora del Departamento de \\ Docencia Universitaria de la \\ Universidad de Costa Rica
}

\author{
Recibido 9-XII-2003 • Aceptado 9-III-2004
}

\begin{abstract}
Resumen: El material contenido en este artículo, representa uno de los productos de la investigación del concepto formación en la Ley Fundamental de Educación de Costa Rica, que consideró entre las preguntas de investigación, la búsqueda de las raíces del concepto en Occidente. Mediante un rastreo en el lenguaje educativo, el acercamiento semántico es una de las etapas del rastreo. El artículo muestra la complejidad semántica del término en el amplio abanico de acepciones y en la enorme posibilidad de puentes léxicos que se pueden establecer desde términos afines y vinculantes.
\end{abstract}

Palabras clave: Campo semántico del concepto "formación", Concepto pedagógico de "formación", Aparición concepto "formación", Significación pedagógica de "formación".

\begin{abstract}
This article includes the findings of a research study on the formation concept included in the Fundamental Law of Costa Rican Education. The research questions seek to find the roots of this concept in the Western world. Along with the scanning of educational language, the semantic approach is used as a scanning step. This articles shows the semantic complexity of the term in a wide range of notions and explores the great possibility of lexical bridges that can be established with similar or related terms.
\end{abstract}

Key words: Semantic field of the "formation" concept, Pedagogical concept of "formation", appearance of the "formation" concept Pedagogical significance of "formation".

\section{Presentación}

El documento posee tres apartados: una introducción, en la que se define la importancia del lenguaje en contexto para el rastreo del concepto 'formación', así como el valor de las fuentes escritas y la riqueza de la interpretación desde la existencia misma de los vacíos conceptuales que la historia reporta. Describe los procedimientos empleados para realizar el rastreo semántico. El segundo, contiene los resultados de la aproximación semántica en la que se desarrollan varios aspectos. En el primero, se recorre la antesala léxica del término 'formación', a partir del término 'forma'. En el segundo, se presenta un primer acercamiento semántico al concepto 'formación' desde la acepción 'dar forma'. Luego se analiza la vinculación del concepto 'formación' con el de 'información'. También se registran los resultados de un análisis del término 'formación' en los diccionarios, principalmente las publicaciones de la Real Academia de la Lengua Española y, finalmente, desde la cadena formación-educar, se revisan otros términos afines al concepto en estudio. El tercer apartado lo constituyen las conclusiones. El documento contiene las referencias bibliográficas consultadas. 


\section{A modo de introducción}

El lenguaje es un recurso vertebrador de la cultura. Por ello, juega un papel decisivo en el ámbito cultural. Reflejado en las producciones literarias, permite rastrear términos y sus acepciones a través del tiempo, en una amplia y rica variedad de fuentes de información escrita. Estas, son recursos fundamentales para construir hipótesis y, seguir vías de comprobación y explicación. Obras literarias, diccionarios, catecismos y enciclopedias, contribuyen a indagar y a justificar las explicaciones que se construyen en un análisis semántico.

En el empleo del diccionario se parte de la consideración de que este es una fuente que autoriza palabras, construcciones y sentidos y los integra para el uso de una comunidad lingüística, dándoles, como señala Álvar Ezquerra (1983), fuerza de ley. Desde la perspectiva de este autor, un diccionario es un objeto sociocultural, cuyo texto está acotado, es decir, que lo que no está en él, no pertenece a la lengua. El diccionario se valora como un objeto sociocultural que expresa una ideología y transmite una visión particular del mundo, pero también, es una obra didáctica, una obra literaria, un texto y una praxis en tanto producto generado por las necesidades, los usos, las normas de construcción o la comercialización.

Un rastreo semántico no es sencillo, toda vez que el contexto en el cual se indaga, resulta complejo y variable, porque un contexto cualquiera en el cual se construyen los términos a lo largo del tiempo y en distintas geografías, lleva a considerar las producciones culturales, concretamente las de la lengua, y en esa línea, la complejidad es inminente. En este caso concreto, España es el espacio geográfico seleccionado para rastrear en el lenguaje educativo, el concepto de interés.

El interés, por la historia semántica de un concepto pedagógico como es el de formación, tiene asociado al desarrollo del concepto en esa historia, el valor emocional.
Este juega un papel importante, por cuanto asume y le imprime variación según el contexto -circunstancias concretas en las que el concepto existe- y la temporalidad. Una palabra puede variar en el tiempo y en el espacio, pero también puede variar su uso, ser sustituida o simplemente perderse. En el caso del concepto formación, es posible que esto también haya ocurrido, y es un aspecto que permite construir preguntas e hipótesis de trabajo.

$\mathrm{Al}$ realizar un trabajo semántico, se reconoce también, el hecho de que cada palabra en un idioma o una lengua, ha tenido una historia semántica propia y particular, que puede ser rastreada en el recorrido de términos afines que constituyen lo que podemos llamar, el campo de significación semántica. Cuando una palabra emerge, tiende a incorporarse, cubriendo a otros vocablos de los que no puede separarse o diferenciarse (Honore, 1980). Este es también el caso del concepto formación, que como se verá, se camufla con otros, como por ejemplo, con educación, enseñanza, perfeccionamiento, capacitación.

En el proceso de conocimiento de un vocablo, de una palabra o de sus voces en particular, se generan una gran cantidad de ausencias y vacíos conceptuales y esto obliga a echar mano del contenido léxico de otros dialectos y lenguas afines, o bien, a ir descubriendo senderos desde campos semánticos colaterales y adyacentes, para develar la historia que tienen las ideas o las palabras, en este caso, vinculantes con la palabra formación.

En este rastreo, se partió de que los conceptos representan las imágenes que el ser humano ha elaborado de los eventos y que éste, recurre al lenguaje como expresión de esas representaciones mentales que el mismo informa. En ese proceso de interpretación a partir del lenguaje para conocer las representaciones mentales de los conceptos, la reflexión del investigador ocupa un lugar fundamental: todo lo que no puede ser reflexionado ni interpretado, queda fuera del área de pensamiento (Trujillo, 1996). 
Pero al ser el lenguaje continuo como lo es la realidad, y al participar de la diversidad de los grupos humanos en los espacios y tiempos en que se estudia, se aprecia que las realizaciones producidas por el lenguaje son únicas. Por lo tanto, existe un espectro de variación, que lo da precisamente, los planos de codificación que poseamos. En ese sentido, el nivel gramatical, puede ser de gran utilidad, pero también el nivel simbólico. Es en el nivel simbólico donde se pueden encontrar más matices del pensamiento y por lo tanto, más matices de la significación.

En este trabajo, se ha tenido una limitación y una ventaja de manera simultánea. Al tomar como base únicamente el lenguaje escrito y en múltiples momentos narrado a través de los procesos de interpretación que han hecho algunos de los autores consultados, se posee una riqueza interpretativa. Numerosos autores han recurrido en sus traducciones a fuentes que están en idiomas como el latín o el griego y también han carecido en muchos momentos de información acerca del lenguaje coloquial en los diferentes espacios y tiempos revisados. Esto obliga a objetivar la interpretación, a fin de no caer en la seducción por las posiciones que puedan sernos afines o a rechazar aquellas que producen más aversión.

El método que se construyó para realizar la aproximación semántica, comprendió un rastreo al concepto mediante una exhaustiva revisión documental en fuentes de información en España. De una cuidadosa selección de diccionarios en español y enciclopedias, se procuró la identificación del término con sus acepciones, siguiendo un orden cronológico en la obras consultadas; posteriormente se identificaron en las acepciones, palabras clave vinculadas con el término formación que sirvieron para construir redes semánticas. Desde las redes construidas, se reflexionó el concepto.

\section{Aproximación semántica}

\section{a. La antesala léxica del término 'formación'}

En un sentido estrictamente pedagógico, formación es un término nuevo (García Carrasco, 1985), cuyas raíces se encuentran en el término 'forma'. Se dice, estrictamente pedagógico, porque un término puede tener, como en este caso, un amplio abanico semántico, que induce la configuración de diversas representaciones intelectuales y por tanto, puede servir para numerosos usos. Los diccionarios consultados, dan cuenta de la diversidad de significaciones que se han dado al término y de las cuales se hace mención en líneas posteriores.

El concepto formación en el ámbito pedagógico, constituye una modalidad específica, del concepto formación como totalidad (García Hoz, 1970). Interesó, sin embargo, focalizar en el sentido pedagógico, sin omitir las referencias necesarias a otros campos semánticos a los que las distintas acepciones refieren.

Todo nuevo concepto, necesita de una nueva palabra que lo designe de manera puntual. El lenguaje juega un papel importante en ese cometido, condicionado por el contexto por una parte, y por su empleo, por otra. De allí deriva el o los significados que evocan las palabras. Interlocutores, contextos y objetos, por tanto, son elementos configuradores del sentido y significación de un término, de tal manera que ha sido difícil plantear una unicidad temática, aspecto que ha sido recurrente en este acercamiento.

En el pensamiento occidental, como término, 'formación' derivó del ámbito semántico que proporcionó la palabra 'forma', por lo fue necesario hacer un acercamiento a las nociones que se encuentran involucradas en el término para analizar cuál de las múltiples posibles documentadas, es la más cercana a la perspectiva pedagógica.

'Forma' se reporta como un semicultismo. Como tal, se aceptaría que ingresó 
al castellano procedente del latín fōma, con algunas modificaciones de tipo fonético, principalmente. Como semicultismo antiguo, se encuentra documentado en el año $1206^{1}$. Corominas refiere a la probabilidad de que el concepto se empleara en otros idiomas, pero fue a partir del siglo XVIII, cuando su uso fue más frecuente (Corominas y Pascual, 1984). Hay evidencias de su empleo en glosarios medievales a partir del siglo XIII hasta el siglo XV ${ }^{2}$.

A pesar de las abundantes referencias bibliográficas que ofrece la pluralidad semántica del término ${ }^{3}$, las acepciones con carácter educativo, fueron tardías. A Occidente penetró en principio, en la perspectiva filosófica, especialmente, en el ámbito ontológico (García Carrasco y García del Dujo, 1996). En tal sentido, 'fōrma' hace referencia a 'figura', 'imagen', 'configuración', 'hermosura'4, 'contorno' (Merani, 1983), acepciones que evocan aquello que es captable por medio de los sentidos y que aluden al aspecto exterior de las cosas u objetos, a la 'apariencia' (Foulquié,1976; De Cobarrubias,1943) ${ }^{5}$. En un sentido filosófico, la acepción primera de 'forma' es 'lo que hace que algo sea lo que es' (quod dat esse rei), contraponiéndose a la idea de materia. La materia expresaría el contenido indiferenciado por sí misma y la 'forma' la que provoca la determinación, la que configura (García Hoz, op. cit.) y otorga una 'imagen', 'apariencia' o 'figura'.

En una clara oposición al fondo, a la esencia, en el pensamiento griego se asumió una diferenciación entre 'figura' y 'forma'. 'Forma' aludía a la figura interna de las cosas captable solamente por la mente. Es la 'idea' de Demócrito y de Platón, en cuanto forma esencial de toda realidad existente. Este término, fue luego vertido al latín como forma, species, notio y genus (Trucco, 1935).

En el pensamiento griego, una de las preocupaciones filosóficas estuvo en la naturaleza de las cosas. Esta se expresó en la relación materia-forma y luego se trasladó al pensamiento de Occidente (García Carrasco y García del Dujo, op. cit.). Así por ejemplo, el concepto 'forma' en Aristóteles, fue llevado a muchas obras de física y de metafísica. Se le reconoce como causa formal, de modo antagónico a causa material. También el concepto 'forma' prestó al sistema aristotélico, un principio de clasificación lógica y ontológica de mucha importancia en el modelo matemático. Aunque se reconoce que la idea aristotélica de 'forma', en el significado derivado del par materia-forma, ha dado mucho problemas ${ }^{6}$, lo cierto es que a partir de Aristóteles y de la Escolástica, el término se conceptualizó como la unidad de composición, que concierta el mayor grado de lo diferente bajo la supeditación total a una unidad o principio homogéneo. Ese principio unificador, actúa, es activo, por lo que 'forma' deviene, es decir, es perfeccionable ${ }^{7}$. Este matiz semántico es por el que podría asomar alguna de las acepciones del concepto 'formación', cual es 'enseñar', en la voz 'perfeccionar'.

En Kant, el término 'forma' ofrece novedades (Trucco op. cit). En su doctrina de las formas puras de la sensibilidad, muestra que, la 'forma' es, lo que hace que lo que hay en un fenómeno de diverso (en la sensación), pueda ser ordenado en ciertas relaciones. En Kant fue donde el término tomó derecho de ciudadanía, una cierta identidad, en la medida en que significa o toma sentido de orden, norma, regla, y recupera la nota de universalidad (Laeng, 1979).

En la filosofía postkantiana, el término 'forma' ha sido entendido no como un a priori, sino como aquello que es susceptible de abarcar cualquier contenido. Por lo tanto, se aproxima más a la noción del par contenido-forma (Ferrater, 1980; García Hoz, op. cit. $)^{8}$, al igual que al significado de 'forma' en música, que refiere al aspecto exterior, al cómo se presenta una composición.

Posteriormente, en el ámbito de las corrientes empiristas y positivas, el concepto en el siglo XVI, pierde con frecuencia, la 
prioridad kantiana y tiende a reducirse a relaciones que pueden generalizarse, por la simple verificación de una constante o regularidad comprobada en los hechos. De ahí que en las ciencias modernas, 'forma' se sustituya por términos como 'estructura' (Corominas, 1967, pág. 168) ${ }^{9}$, con un significado de regularidad. En las ciencias biológicas, el término se ha asociado más al aspecto de estructura estática, que al funcionamiento dinámico. Tal es el caso de la morfología descriptiva, la morfología sistemática o la anatomía.

A partir de la relación materia-forma, se alude a que, siendo la materia lo determinable y forma la determinación, es posible hacer un correlato con el par potencia-acto, es decir, la materia cobra una manera determinada potencialmente contenida en ella, por efecto del acto. 'Dar forma' en esta perspectiva, es extraer de la materia la forma contenida en ella. Desde esta posición, la formación sería producto de actuar sobre la materia y estaría en la idea de 'conformar'10, en el tanto la materia no se logra separar de la forma, sino está con ella (García Hoz, op. cit., pág. 430).

En algunas ocasiones, 'forma' refiere a características estáticas de una realidad. Con esa acepción se asocian las voces de 'molde', 'modelo' (Sainz de Robles, 1971), 'horma', 'silueta', 'apariencia', 'contextura', 'estampa' y 'efigie', así como 'proporción' y 'disposición', en tanto orden de los aspectos exteriores. Todas ellas, remiten a la posibilidad de la existencia de aquello interno que es causa de esa exterioridad, y por lo tanto, a los aspectos circunscritos en la realidad exterior de las cosas.

Siendo 'forma' un término asociado a la sensorialidad y en ese sentido, a la percepción, es comprensible que se introdujera posteriormente, en la Teoría de la Gestalt, como un término útil en la explicación de la organización perceptiva unitaria de los datos sensoriales, aspecto que contribuye sustantivamente, en la distinción y en el reconocimiento de los objetos. Desde una teoría de la percepción, se reconoce que en los procesos perceptivos existen estructuras de proximidad o vecindad llamados semejantes, que son los responsables de la unidad y calidad de los contenidos de un mismo campo. Y esos semejantes tendrían lugar en la intuición de complejas situaciones: se darían en los animales y en la formación del lenguaje y del pensamiento. Traducido a la esfera psicológica, las percepciones estarían en la base del aprendizaje. Esta idea resulta importante para la formulación de la existencia de un acceso a la interioridad, y en consecuencia, a la posibilidad de realizar actividad conducente a elaborar nociones, es decir, aquello que es percibido por el entendimiento. De esta manera, la palabra 'forma', denotaría el acto de elaborar nociones a partir de la exterioridad del objeto que es percibido.

El término 'forma' se vincula también con otras voces: 'modelo' (Sainz de Robles, op. cit.), 'fórmula' y 'modo de proceder'11, de 'hacer las cosas', como por ejemplo, escribir.

En otra dimensión, el concepto alude a 'causa'. Por ejemplo, para Cassirer En Ferrater, 1980), en una perspectiva metodológica, la realidad puede ser concebida basada en un método de causas o en un método de formas. La filosofía antigua y la medieval, se basaban en el método de causas. Desde un método de causas, existen por ejemplo, causas eficientes que producen sobre la materia preyacente una forma determinada, potencialmente presente en ella. Bajo esta óptica, el producto de 'dar forma', sería la formación. O sea, una actividad productiva (García Hoz, op. cit.). Pero en la actualidad, se emplea más el sentido de estructuras, en tanto una concepción de formas.

El método de formas, llevado al territorio de las ciencias culturales, permite alcanzar mejores resultados interpretativos. Para Cassirer, el origen de la función simbólica, en cuanto objeto fundamental de las ciencias que estudian la cultura y de acuerdo con su idea de animal symbolicum, no es 
comprensible por los científicos causales, porque en lo que refiere a lo cultural, todo devenir permanece dentro de un determinado ser, es decir, dentro de la forma en general. En ese sentido, la idea de Platón, del devenir hacia el ser.

A partir de estas consideraciones generales del concepto 'forma', se aprecia entonces, una importante gama de términos que se pueden colocar como acepciones que hacen referencia a lo exterior: 'figura', 'imagen', 'configuración', 'horma', 'apariencia de las cosas', 'manera de presentar alguna cosa', 'manera de ser o de expresar su pensamiento' (Sainz de Robles, op. cit.; Foulquié, 1976), 'hechura', 'formación' (como palabra derivada en Corominas, 1987), 'estampa', 'efigie', 'silueta', 'contorno', 'conformación', 'contextura', 'constitución', 'disposición', 'proporción', 'diseño', 'dibujo', 'molde', 'matriz', 'modelo', 'modo', 'traza o plan'12, 'proceder', 'tamaño' y 'formato' (Sainz de Robles, op. cit.; Merani, 1983; Real Academia Española. (1970); Casares, 1984). Una referencia a 'forma' como 'esencia o perfección cristiana', se encuentra también documentada en el siglo XIII (Alonso Pedraz, op. cit.) ${ }^{13}$.

Pero en otro conjunto de voces, hay acepciones que remiten a la acción. Se trata de términos que están más vinculados con la acción de 'dar forma' o 'formar' tales como: 'fabricar', 'plasmar' 'figurar', 'pintar'14, 'constituir', 'conformar'15, 'producir', 'componer', 'crear'16, 'integrar', 'constituir' y 'moldear algo'. Y una breve acepción a 'método' y 'conducta' (Enciclopedia Vniversal Ilvstrada Evropeo-Americana). Estos elementos se han considerado en esta investigación, como los puentes léxicos que permiten enlazar el término 'forma' con el término 'formar', y sirven como recurso para arribar al concepto de 'formación'.

Esta gama de significaciones, ha posibilitado, desde las fuentes consultadas, la construcción del siguiente brazo lexicográfico (Figura No. 1), en el cual, quedan representadas las acepciones y puentes semánticos entre 'forma' y 'formar' que permite valorar la relación.
Figura $\mathrm{N}^{\circ} 1$

Brazo lexicográfico: forma-formar

Forma

Formar

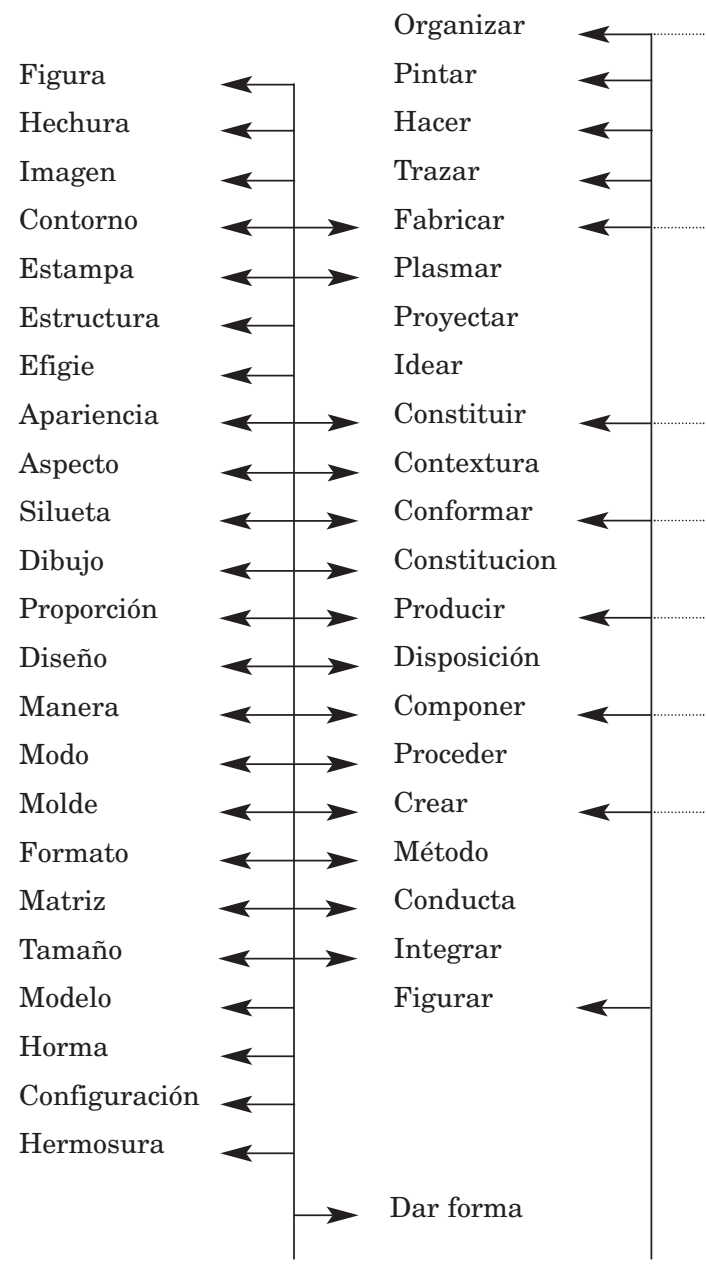

\section{b. 'Dar forma': el primer acercamiento semántico al concepto 'formación'}

Entre las acepciones que interesa destacar por su proximidad con la voz 'formación', es sin duda, aquella que remite desde 'forma' a la acción de 'formar': 'dar forma'. 
Se ha señalado con García Hoz (op. cit.), que a partir de la noción de 'forma' como acto, es posible un acercamiento a la formación como la acción que resulta de 'dar forma', es decir, de 'formar'. En este sentido, cobra significación la acepción que en el Diccionario de la Real Academia de la Lengua Española, se reporta para la voz 'formación': 'acción y efecto de formar'. Claramente, 'formar' es el concepto que se documenta con un uso más frecuente en todas las épocas (Corominas y Pascual, op. cit.). Proveniente del latín formare, es una palabra derivada y documentada en el período 1220-50 (Corominas, op. cit.). Por lo general aparece como analogía de 'forma' (Casares, op. cit.) y con las acepciones pedagógicas más claramente señaladas: 'instruir', 'educar', 'enseñar' (Diccionario de uso del español actual, 1996); Cuervo, 1992).

'Formar' toma una amplia gama de acepciones desde diferentes fuentes. Una, desde la noción de 'hacer, fabricar, constituir, concebir o moldear algo', aparecen las voces: 'dar forma determinada a objetos físicos' (Boggs, R.S. y otros, 1946, pág. 265)17; 'conformar o construir algo'; 'pintar, figurar o plasmar'; 'crear de la nada o dar el ser'; 'crear en el pensamiento ideas, opiniones o teorías'; 'trazar, idear planes o proyectos'; 'integrar o constituir un conjunto de cosas o personas' y la noción propiamente educativa, en la idea de 'educar'18, 'hacer o desarrollar aptitud o toda la personalidad'. La Real Academia Española, describe aún más esta acepción: 'adquirir una persona más o menos desarrollo, aptitud o habilidad en lo físico o en lo moral'. Otra, desde la noción de organizar personas en un orden determinado (Cuervo, op. cit.). De esta última noción, se reconoce como producto de la acción de formar personas, la acepción más refinada concerniente a la formación militar (García Hoz, 1970) ${ }^{19}$ o a la formación en congregaciones de tipo religioso. 20

Alonso Pedraz, documenta la palabra 'formación' a partir del siglo XV y remite a las acepciones de 'forma' y 'acción de formar', como se ilustra en el siguiente ejemplo: "llámanse ediciones que quiere dezir obras o formaciones o formadas de nuevo." (Alonso Pedraz, op. cit., pág. 1162) ${ }^{21}$

Desde esta diversa gama de significaciones, queda en evidencia que la palabra 'forma', a partir de la acción y efecto de 'formar', es el término que más acerca al concepto de ‘formación'. A esta idea se añade un hecho claro que resulta del análisis que realizan García Carrasco y García del Dujo en relación con el concepto de 'formación' desde la investigación que realizara Trujillo (en García Carrasco y García del Dujo, op. cit.). Señalan los autores, que tanto los vocablos educación como formación, son auténticos neologismos desde el punto de vista pedagógico y que la actual problemática formativa, si bien tiene entre sus sememas la idea de 'forma', debe haber algún lugar por donde ingresó el concepto al léxico pedagógico. Para ellos, la evolución semántica del concepto deja evidencia del ingreso antropológico en la conducta humana inteligente.

El estudio de Trujillo, reporta alrededor de 400 palabras que el autor ha organizado en cinco cortes, reflejo de la organización léxica del campo. Estos poseen un orden cronológico, por períodos, en los cuales se organizan archisememas que representan el atributo en torno al cual se agrupan los calificativos. En los cinco cortes, la inteligencia hace acopio de una diáspora semántica que se vierte en todas las ramificaciones. Un resumen de la investigación referida, permite apreciar la información:

De esta referencia señalada por García Carrasco y García del Dujo, es claro que, en el caso de la palabra 'formación' relacionada con la palabra 'formar', se evoca la idea de acción que se ubica con mayor predominio en el campo de la valoración intelectual. No obstante, el empleo que se realice del término, es el que determina la significación. Las experiencias prácticas y sociales, hacen recaer la significación en alguna de 


\section{Cuadro $\mathrm{N}^{\circ} 1$}

Organización léxica del campo por cortes, según archisememas, cualidades que evoca y consecuencias según Trujillo

\begin{tabular}{|c|c|c|c|c|}
\hline Corte & Período & Archisemema & $\begin{array}{l}\text { Cualidades } \\
\text { que evoca }\end{array}$ & $\begin{array}{c}\text { Consecuencias del } \\
\text { archisemema }\end{array}$ \\
\hline $1^{\circ}$ & Siglo XII & 'que actúa con previsión' & $\begin{array}{l}\text { 1. Acordado, cuerdo, mensurado, } \\
\text { membrado. } \\
\text { 2. Sabidor como poseedor del } \\
\text { rasgo de dominar el ámbito de } \\
\text { la experiencia. Dominio que se } \\
\text { ejerce por la capacidad pondera- } \\
\text { da (cuerda, mensurada, cuerda) } \\
\text { de toma de decisiones }\end{array}$ & $\begin{array}{l}\text { Dominio de la acción del } \\
\text { hombre; instalación de la } \\
\text { excelencia humana; control } \\
\text { de acciones en función de } \\
\text { metas culturalmente } \\
\text { organizadas }\end{array}$ \\
\hline $2^{\circ}$ & $\begin{array}{l}\text { Siglos } \\
\text { XIII y XVI }\end{array}$ & $\begin{array}{l}\text { 1. Previsión en el saber } \\
\text { práctico o de experiencia: } \\
\text { listo, sagaz. } \\
\text { 2. Prever en función del } \\
\text { conocimiento aprendido por } \\
\text { el canal discursivo: docto }\end{array}$ & $\begin{array}{l}\text { Por } 1 \text {, inteligencia natural, } \\
\text { talento natural; por } 2 \text {, un nivel } \\
\text { mayor de esas cualidades }\end{array}$ & $\begin{array}{l}\text { Procesos de diferenciación } \\
\text { entre saberes (ciencias y } \\
\text { letras). Acciones formativas } \\
\text { en tres estadios: conceptual, } \\
\text { recognitivo, técnico }\end{array}$ \\
\hline $3^{\circ}$ & $\begin{array}{l}\text { Siglos XVI } \\
\text { y XVIII }\end{array}$ & $\begin{array}{l}\text { Discreto. Contiene las } \\
\text { voces: prudencia, saber, } \\
\text { habilidad, inteligencia }\end{array}$ & $\begin{array}{l}\text { Se agrupan en tres campos. } \\
\text { 1. Parte de cuerdo y prudente } \\
\text { hasta llegar a sagaz y astuto. } \\
\text { 2. Comprende los conceptos de } \\
\text { sabio, letrado, erudito y versado. } \\
\text { 3. Comprende los términos: } \\
\text { práctico, diestro, experto, } \\
\text { ingenioso, industrioso y capaz. } \\
\text { A partir de estos tres campos, } \\
\text { se aprecia la valoración de la } \\
\text { inteligencia como campo que } \\
\text { determina a la formación }\end{array}$ & $\begin{array}{l}\text { Formación centrada en la ad- } \\
\text { quisición de títulos. } \\
\text { Formación como atribución } \\
\text { que se da a quien sabe y sabe } \\
\text { hacer las cosas }\end{array}$ \\
\hline $4^{\circ}$ & $\begin{array}{l}\text { Siglos } \\
\text { XVIII y } \\
\text { finales del } \\
\text { XIX }\end{array}$ & $\begin{array}{l}\text { Incluye los términos sabio, } \\
\text { inteligente e instruido. De } \\
\text { ellos se desprenden } \\
\text { ramificaciones diversas que } \\
\text { traen las voces: perspicaz, } \\
\text { capaz, entendido, } \\
\text { penetrador, agudo, sutil, } \\
\text { despejado, claro, vivo, hábil, } \\
\text { diestro, mañoso, entre otras }\end{array}$ & $\begin{array}{l}\text { Valoración creciente al saber } \\
\text { abstracto }\end{array}$ & $\begin{array}{l}\text { Reconocimiento a saberes } \\
\text { técnicos en la perspectiva } \\
\text { habermasiana }\end{array}$ \\
\hline $5^{\circ}$ & $\begin{array}{l}\text { Finales del } \\
\text { siglo XIX } \\
\text { hasta la } \\
\text { actualidad }\end{array}$ & $\begin{array}{l}\text { Inteligente, con ramificaciones } \\
\text { que se agrupan en cuatro } \\
\text { campos: } 1 . \text { El de los términos } \\
\text { hábil (experto, ducho, perito), } \\
\text { diestro (virtuoso, habilidoso). } \\
\text { 2. El de los términos relativos } \\
\text { al que sabe con una gama de } \\
\text { voces referidas a tal condición } \\
\text { (instruido, conocedor, } \\
\text { intelectual, culto, leído, } \\
\text { sabio). 3. El que refiere a } \\
\text { cualidades para alcanzar } \\
\text { fines (astuto, avisado, listo). } \\
\text { 4. Incluye el semema juicioso }\end{array}$ & Amplio abanico de nociones & $\begin{array}{l}\text { Especialización de los ámbitos } \\
\text { de formación; sectorialización } \\
\text { de los juicios de valoración } \\
\text { intelectual; apertura semanti- } \\
\text { ca de la noción de formación; } \\
\text { efectos importantes en el empleo } \\
\text { curricular que tornaría más } \\
\text { complejo el diseño curricular }\end{array}$ \\
\hline
\end{tabular}


las acepciones reportadas. De ahí la importancia de revisar el término en diferentes contextos a lo largo del tiempo y conocer en la esfera educativa, las significaciones con las que el término no sólo se ha acuñado, sino ha ingresado al campo pedagógico.

\section{c. Formación e información}

'Forma' como 'estructura' e 'información' como 'estructura', son dos de las relaciones que se pueden construir, a partir de alguna de las voces encontradas en diversas fuentes. El término 'informar', proveniente del latín infōrmfāre que significa 'formar', aparece como cultismo en el siglo XV (Alonso Pedraz, op. cit., pág. 1259) en el año 1444 (Corominas, 1967, pág. 278) y encuentra una serie de voces en el Diccionario de la Real Academia Española de la Lengua (op. cit.) 22 : "enterar, dar noticia de una cosa; formar, perfeccionar a uno por medio de la instrucción y buena crianza; dar forma sustancial a una cosa, dictaminar un cuerpo consultivo, un funcionario o cualquier persona perita, un asunto de su respectiva competencia; hablar en estrados los fiscales y abogados" (Real Academia Española, op. cit., pág. 771) ${ }^{23}$. Nótese por ejemplo, las reiteradas referencias de carácter educativo que se encuentran en algunas de las acepciones citadas. Asimismo, se encuentra una amplísima riqueza de sinónimos en Sáinz de Robles (op. cit., pág. 626) tales como: 'enterar, instruir, iniciar, imponer, intimar, indicar, investigar, orientar, participar, comunicar, anunciar, avisar, noticiar, advertir, notificar, requerir, expresar, revelar, publicar, dar cuenta, reseñar, poner al corriente, dar razón, dar aviso, facilitar datos, vivir en conocimiento, tomar voz beber en buena fuente'.

Traemos a colación a Mosterín en su disertación acerca de la cultura como información. De acuerdo con él, la información se puede formular en tres sentidos: uno, como información sintáctica o estructura, que refiere a la forma (o estructura) y hace referencia a un alfabeto, marco o código, pero no es el relativo a un objeto o a un receptor ${ }^{24}$. Otro, es la información semántica, como correlación ${ }^{25}$. Y el tercero, es la información pragmática, aquella en la que se establece una relación entre el mensaje y el receptor. El mensaje 'in-forma' al receptor induciendo algún cambio en él ${ }^{26}$.

Se indicaba en líneas anteriores, que el término 'forma', en el ámbito de las corrientes empiristas y positivas, tiende a reducirse a relaciones que pueden generalizarse, por la simple verificación de una constante o regularidad comprobada en los hechos. Es frecuente encontrar entonces, en las ciencias modernas, una sustitución del concepto 'forma', por términos sustantivos y no verbales, como 'estructura', con un significado de regularidad, asociándose más al aspecto de estructura estática, que al funcionamiento dinámico. Tal es el caso de las formas geológicas, llamadas formaciones geológicas, que dan cuenta de los estados morfológicos de la corteza terrestre y refieren a los aspectos estructurales de ciertos sectores o formaciones (formación ígnea, neptúnica, etc.). De igual modo, en el caso de ciertos casos como el militar, la reunión ordenada de un cuerpo de tropas, alude a la estructura de la formación militar. En esta idea, forma es orden, organización y composición (Diccionario Enciclopédico Hispano-Americano de Literatura, Ciencias y Artes (op. cit., págs. 893-894). De ahí que en este caso en concreto, se abre un camino para establecer una relación entre, la forma con la estructura y, la estructura con la información.

Se ha señalado en otro apartado, que al acto de 'dar forma' se le conoce con el término de 'formar', mientras que al efecto de 'dar forma' se le denomina en una de las voces, 'formación'. No es entonces de extrañar, que en el conjunto de las acepciones de formación se encuentre 'informar' en la idea de 'in-formar', es decir, de incorporar datos, ideas, información.

$\mathrm{Al}$ respecto de estas relaciones, el término 'instrucción', como una de las 
voces de 'formación', aparece como 'informar' (Diccionario de uso del español actual (op. cit.), por lo que también se puede vincular con el quinto corte léxico (correspondiente a finales del siglo XIX hasta la actualidad) que propone Trujillo relativo al archisemema inteligente en el cuarto campo: el de los términos relativos al que sabe y que incluye una gama de voces referidas a tal condición, tales como instruido, conocedor, intelectual, culto, leído, sabio.

Se podría inferir que, por la vía de 'informar', pudo haber entrado también el término 'formación' como concepto pedagógico. 'Dar información', es decir 'informar', que pudo haber sufrido cambios fonéticos perdiendo el prefijo 'in' hasta quedar 'formación' como parte de un lenguaje coloquial que se asentó con matices semánticos más elaborados posteriormente.

\section{d. La formación en los diccionarios de la Real Academia de la Lengua Española y otros}

García Carrasco y García Del Dujo llaman la atención desde el estudio de Trujillo (García Carrasco, op. cit.) desde el Diccionario de la Real Academia Española de la Lengua, a que el término formación no está descrito, ni hubo necesidad de recurrir al término ni a otros vocablos colaterales para atender a la formación y educación. Esa idea, abre entonces la posibilidad de seguir el rastreo en otros escenarios.

En apartados anteriores se mencionó que, es en la voz 'formar', donde la palabra formación, encuentra un nicho para establecerse, cuando se hace referencia a la acción y efecto de 'formar', como producto de la descripción del término 'forma'. Quiere decir, que en los diccionarios es frecuente encontrar establecida una vía al concepto de 'formación' mediante el puente semántico con la palabra 'formar' desde el término 'forma'.

García Hoz (1970), al analizar el término 'formación', informa que, la Real
Academia de la Lengua le confiere un doble significado tal y como se ha descrito: 'acción y efecto de dar forma o formar', pero que carece realmente de una significación pedagógica y deja abierta una leve rendija por donde se cuelan dos acepciones: 'criar, educar, adiestrar' y: 'adquirir una persona más o menos desarrollo, aptitud o habilidad en lo físico o en lo moral'. En ese sentido dice el autor, que las voces aluden más a la idea de formarse que a la de formar.

En el estudio efectuado, se verifica que, la palabra 'formación', en esas fuentes, se estructura con preferencia desde la acción, en concreto, con 'dar forma' o 'formar' (del latín formāre ${ }^{27}$ ), cuando se trata de relacionarla con la educación. Al respecto las voces 'educar' y 'criar', son las que refieren explícitamente, con significación pedagógica. Desde el Diccionario de la Lengua Española, la voz educar, proveniente del latín ēdūcāre, se documenta desde el año 1623 (Corominas, op. cit., pág. 224) y se coloca en un amplio sentido pedagógico a través de sus acepciones: 'dirigir, encaminar, doctrinar', 'desarrollar o perfeccionar facultades intelectuales y morales por medio de preceptos', 'desarrollar fuerzas físicas por medio del ejercicio para hacerlas aptas para su fin', 'perfeccionar, afinar los sentidos, afinar el gusto', enseñar los buenos usos de urbanidad' (Real Academia Española, op. cit., pág. 525), 'hacer sentir al niño de su estado primario, o sea, hacer salir de él (en actualizar) lo que posee virtualmente', 'formar por medio de la educación', 'dirigir a formación moral e intelectual de un hombre' (Foulquié, op. cit., pág. 155). Desde esas acepciones, se incorpora la idea de la acción como parte constitutiva del término y se abre, no sólo un abanico semántico mayor al ingresar en la descripción, nuevos términos: dirigir, encaminar, doctrinar, desarrollar, perfeccionar, enseñar, sino la posibilidad de encontrar otros matices que encierran connotaciones ideológicas diversas. No obstante, estas voces, tal y como se puede ver en las fuentes consultadas, 
son muy recientes. En estudios de léxico medieval (Boggs y otros, op. cit.; Alonso Pedraz, op. cit.), no aparece el término.

\section{e. Formación-educar y otros términos afines}

Al indagar acerca del concepto 'educar', se aprecian las siguientes cadenas de relaciones tomando por eslabones de la cadena, formación y educar:

Formación-educar-perfeccionar. La acepción de perfeccionar, refiere concretamente a 'acabar enteramente una obra, puliéndola y dejándola sin el más leve defecto' (Diccionario Enciclopédico HispanoAmericano de Literatura, Ciencias y Artes, op. cit., pág. 134. Real Academia Española, op. cit., pág. 1043), que introduce un cierto determinismo y una finalidad. El concepto también posee una rica cantidad de sinónimos (Sainz de Robles (op. cit., pág. 831): 'afinar, refinar', 'pulir', 'prosperar', 'mejorar', 'adelantar', 'progresar', 'limar', 'idealizar', 'sutilizar', 'alambicar', 'acendrar', 'retocar', 'acrisolar', 'acabar', 'coronar', 'completar', 'conducir', 'poner en punto', 'dar la última pincelada', 'echar o poner el sello', 'ponerlos puntos sobre las íes', 'hacerse', 'lograrse', 'llegar al colmo', 'dar la hora', 'no haber más que pedir'.

Formación-educar-adiestrar. Adiestrar como voz no entró al castellano en el medioevo. En el caso del término adiestrar, se habilitan otras voces por medio de los sinónimos y antónimos, tales como 'aleccionar', 'ejercitar', 'amaestrar', 'entrenar', 'industriar' (Sainz de Robles, op. cit., pág. 37) y 'afinar', 'refinar', 'sutilizar', 'idealizar', 'pulir', 'pulimentar' y 'limar' (Casares, op. cit., pag. 339). Para la voz adiestrar, la Real Academia Española de la Lengua, ofrece tres acepciones 'hacer diestro', 'enseñar', e 'instruir' (Real Academia Española, op. cit., pág. 28). Una acepción referida al comportamiento, se encuentra en el sentido de: 'hacer contraer al hombre y sobre todo al animal, el hábito de ciertos comportamientos' (Foulquié, op. cit., pág. 16).

Formación-educar-enseñar. El término enseñar, documentado en el año 1140 (Corominas, op. cit., pág. 531) ${ }^{28}$ constituye una voz que tiene un matiz pedagógico muy particular. Primitivamente denotaba la acción de dar una seña a alguien, pero poco a poco fue tomando la connotación de transmitir conocimientos y por extensión se asocia con 'instruir', 'adoctrinar', 'amaestrar con reglas y preceptos', y 'comunicar a otro determinado saber' (Foulquié, op. cit., pág. 164). Aparece como parte del léxico medieval como 'instruir' y 'educar'29 y como 'mostrar'30.

Formación-educar-enseñar-doctrinar $^{31}$. En este último concepto, se establece doctrina como 'enseñanza que se da para instrucción de alguno', con lo cual ingresa el término instrucción ${ }^{32}$. También se abre paso por la vía de los sinónimos y antónimos, la palabra 'catequizar'33. Es un cultismo que en el medioevo se empleaba como 'doctrinar' del latín doctrinare ${ }^{34}$.

Formación-educarenseñar-doctrinar-instruir. En la voz instruir, aparecen como acepciones 'comunicar sistemáticamente ideas, conocimientos o doctrinas', 'dar a conocer a uno el estado de una cosa o informarle de ella', con lo cual, se abren paso además, las acepciones de comunicar e informar (Real Academia Española, op. cit., pág. 779). También se alude '...formar la inteligencia' (Foulquié, op. cit., pág. 251). Es un cultismo de uso en la Edad Media ${ }^{35}$

Formación-educar-dirigir-guiar (Diccionario Enciclopédico Hispano-Americano de Literatura, Ciencias y Artes, op. cit., pág. 723) ${ }^{36}$. En este caso, desde la voz guiar queda instalada la presencia del otro en la acción.

Formación-educar-dirigir- enderezar (Diccionario Enciclopédico HispanoAmericano de Literatura, Ciencias y Artes, op. cit., pág. 723)37. La acepción en la palabra 'rectamente' y 'lugar señalado', instala la dimensión ética y un telos. 
Formación-educar-dirigir-encaminar (Diccionario Enciclopédico HispanoAmericano de Literatura, Ciencias y Artes, op. cit., pág. 723) ${ }^{38}$. De igual modo, el telos y la ética, quedan instauradas a través de las palabras 'intención' y ‘determinado fin'.

Formación-educar-criar. Esta última es una de las voces más antiguas (documentada en el 1097) cuando se revisa el concepto educación y formación. Es cultismo empleado en la Edad Media y tiene un importante campo semántico (Corominas, op. cit., pág. 178). Justamente de este término, se encuentran las acepciones pedagógicas: instituir, educar y dirigir (Diccionario Enciclopédico Hispano-Americano de Literatura, Ciencias y Artes, op. cit., págs. 1307-1308)39.

\section{Conclusiones}

Como se ha podido documentar, la palabra está referida a su origen latino, formación fōrmatro ofrece desde los diversos diccionarios consultados y de varios estudios que se han realizado en torno al origen de términos, especialmente en los medievales, un buen acopio de palabras para construir un repertorio de lenguaje literario y vulgar, desde el cual generar una red lexicográfica, que informe de los puentes que llevan a través de la semántica del término. No obstante, se observa desde esta amplia gama de acepciones y voces, que al igual que ocurre con el término educación, se pierde o desdibuja la precisión conceptual, con lo cual no resulta sencillo llegar a una sola definición. Pero también deja más espacio para el análisis de la evolución del concepto, especialmente a partir de las palabras derivadas, que hacen viable la construcción de campos léxicos.

El término 'forma' como antesala del concepto ofrece una amplia gama de acepciones desde su ingreso a Occidente como referencia a aquello que es exterior, a la apariencia y que desde el plano filosófico, resulta contrario a la materia. La relación materia-forma del pensamiento griego, trasladada a Occidente, permite ver que 'forma' devino en la acepción de lo perfeccionable, matiz semántico por el que podría asomar alguna de las acepciones pedagógicas del concepto 'formación', cual es: 'enseñar', en la voz 'perfeccionar'.

No obstante, es la expresión 'dar forma', a partir de la idea primigenia de que la materia contenida en una forma puede ser modificada por la acción y derivar en otra forma, la que permite abrir la vía de la acción sobre la materia y sirve para comprender los puentes que se han establecido para configurar un universo semántico en el que la formación queda imbricada. Así, en las versiones más recientes, el concepto formación, mediante esos puentes léxicos, se vincula con voces como información, educar, perfeccionar, adiestrar, enseñar, doctrinar, instruir, dirigir, guiar, enderezar, encaminar y criar. Todos ellos, muestran un campo de significaciones pedagógicas que claramente pueden ser entendidas en la idea de que la formación es efecto de una acción sobre el sujeto y puede ser también la acción a la que se somete el sujeto. En una doble semántica, formación es causa y efecto de la acción porque el individuo es 'materia' potencialmente susceptible de ser modificada. Esta, desde luego alude a la condición de educabilidad que posee el ser humano y en esa vía, la formación es correlato de la educación. De particular interés puede resulta la voz 'informar' que conduce a la idea de formar o dar forma, por medio de una acción que es la instrucción, o la crianza. En la actualidad, el concepto en el entramado de voces que complejizan la significación con nuevas acepciones sinónimas, ofrece un rico escenario para ubicar la formación como un campo de significación en el que predomina la acción y el efecto de dar forma por la intervención que se puede realizar en los individuos y donde la escuela se convierte en una de los escenarios sociales legitimados para tal efecto. 
Finalmente, el acercamiento permitió mostrar que aunque el concepto en su dimensión pedagógica es neologismo vinculado con el campo de la valoración intelectual, tiene, en 'educar' en la voz 'criar' y en 'dar forma', sus mejores nichos explicativos y la posibilidad de ser situado entre los siglos XV y XVI.

\section{Notas}

1. Corominas (1987) documenta: Cejador IX, 166; Glosas de Silos; documentos de 1206; textos medievales; Alonso de Palencia (46d, 143b, 161b, 213d); Elio Antonio Nebrija.

2. Alonso Pedraz (1986) documenta: Berceo: Santo Domingo (c.1230), 328; Evangelio de San Mateo, m.s.esc. 116 (c.1254-70), ed. 1962, c.17, v.2; Alonso de Palencia: vocab. (1490), 46d; Elio Antonio Nebrija: vocabulario español-latín. (c. 1495).

3. Cejador, Julio y Frauca. (1902); Alonso Pedraz, (op. cit.); Corominas (op. cit); Corominas y Pascual (op.cit., págs. 555-556); Casares (1984, pág. 2); Diccionario de uso del espanol actual. (1996); De Miguel (1914, pág. 384); Enciclopedia Vniversal Ilvstrada Evropea-Americana. Tomo XXIV; Merani (1983, pág. 70); Foulquié (1976); García Hoz (op. cit.); Trucco. (1935, pág. 121); Dizionario Enciclopedico Di Pedagogia. Vol. II. (S.f.); Saglio (S.f., págs. 1243-1254); Álvar y otros. (1959); Diccionario Enciclopédico Hispano-Americano de Literatura, Ciencias y Artes. Tomo octavo. (1981); Sainz de Robles (1971); Real Academia Española. (1970); Ferrater (1980); Laeng (1979); Pellicia, Rocca (1977) Vol. IV; Real Academia Española. (1984) Tomos I y II; De Cobarrubias (1943) .

4. Corominas (1984, página 555). Cita primera documentación en Berceo.

5. $\quad \mathrm{Al}$ respecto dice el autor: 'Forma: todo aquello que da ser a la cosa. Tratar en forma desta dicción seria cosa disforme, y assi lo dexo para los lógicos y físicos que tratan ex professo de materia y forma y vulgarmente digo es la figura, el talle y parecer de cualquier cosa. Buena forma de letra, mala forma. Enojarse en forma, enojarse de veras. Hazer una cosa propter forman, hazerla de cumplimiento. Y deste término usan aun los que no saben latín, y assí vale tanto forma como apariencia o cumplimiento'.

6. Uno de los problemas que se citan en Laeng (op. cit.), es si forma y materia son realidades plenas, es decir, si es posible la existencia o no por sí mismas, de formas separadas, porque para Aristóteles es claro que existen formas independientes de la materia. Ferrater (op. cit.), señala también que Aristóteles aunque alude a la existencia de diversidad de formas, no desarrolló la idea, hecho que si hicieron los escolásticos. En relación con la diversidad de formas, podemos citar a Santo Tomás, y la distinción que hace de la forma separada o formae separatae, y la forma adherida o formae adherentes, a la materia. Véase Trucco (op. cit., pág. 121).

7. $\quad \mathrm{Al}$ respecto consúltese el Diccionario Enciclopédico Hispano Americano de Literatura, Ciencias y Artes. Tomo VIII. Op. cit.

8. Para Ferrater los pares materia-forma y contenido-forma, mantienen diferencias conceptuales importantes. Para García, es en el par materiaforma, donde mejor se expresa la noción de forma desde el punto de vista filosófico.

9. Término que entró al castellano en 1580, proveniente del latín structura que significa ‘construcción', 'fabrica', 'arreglo', 'disposición'.

10. Palabra derivada que entra al castellano entre el año 1220 y 1250, proveniente del latín conformare que significa 'dar forma', 'adaptar'.

11. Se documenta a partir del siglo XIII hasta el XV en Berceo: Santo Domingo (c. 1230), 321: 'Quiero con tu conseio prender forma de vida' y como 'forma o manera, forma, ae, modus, i' en Elio Antonio Nebrija: Vocab. esp. lat.

12. Se encuentra en el Fuero de Juzgo (1266) Esc.1,15, en Fernández Llera: Gramática y vocabulario, edición de 1929, s.v. Citado por Alonso Pedraz (op. cit).

13. Citado por el autor: 'Entendió la forma de la perfección'. Documentado en Berceo: San Millán (1235, pág. 21).

14. Estas tres últimas voces las reporta Cuervo (1992 Págs. 346-356). 
15. Corominas (1987), lo documenta como palabra derivada desde 1220-1250, procedente del latín conformare, 'dar forma', 'adaptar', 'conformación'. Lo documenta en Berceo y en Cuervo, Diccionario II, 3659.

16. Para García Hoz, la acción creadora sólo es producto de Dios, por lo que no hay en ella, acción formativa, sino creadora.

17. Lo documentan en Berceo: Loores, 105, Lba $109^{\mathrm{a}}$.

18. También la Real Academia Española, 1984, pág. 654, agrega las acepciones 'criar' y 'adquirir'.

19. También en Real Academia Española, op. cit, pág. 654 aparece la expresión: 'Poner en orden, formar el escuadrón'; 'Colocarse una persona en formación, cortejo’.

20 Por ejemplo, citamos a Aldea Vaquero, Quintín; Marín y Vives/Instituto Enrique Flores/Consejo Superior de Investigaciones Científicas. (1972, pág. 953), refieren por ejemplo a la Congregación de Formacionistas Esclavas de María.

21. Documenta en El Tostado, de Alonso de Madrigal: Sobre Eusebio, I (1455-55), ed. 1506, 17 a.

22. Véase también las ediciones de 1925, de 1956 y de 1970. Aparece también como 'dar forma a una cosa y ponerla en su punto y ser' en De Cobarrubias, (op. cit., pág. 737).

23. También en las ediciones de 1925, página 688; de 1956, página 747 y de 1970, página 745 .

24. Por ejemplo, la información contenida en un viejo papiro incomprensible para un hispano hablante, es simplemente información sintáctica.

25. Se correlacionan las señales con emisores o eventos. En el caso del papiro, podemos reconocer en él algunos dibujos que nos informan de algún tipo de escritura, pero sin llegar a entender realmente el sentido y significado de la información que éste contiene.

26. Se trata en nuestro ejemplo, de la información contenida en el papiro, comprensible para el receptor y que puede ejercer influencia en su marco de valores, de acciones o de conocimientos. Este último aspecto es fundamental. Se trata de que la forma puede tener diferentes efectos sobre el receptor que informa y según cuál sea, portará un tipo de información pragmática para ese receptor, es decir, tendrá un contenido diferente.

27. Significa 'dar forma a una cosa', 'juntar o congregar diferentes personas o cosas uniéndolas entre sí para que hagan aquello cuerpo moral y éstos un todo', 'producir o hacer', 'criar, educar', 'poner en orden'. En Diccionario Enciclopédico Hispano-Americano de Literatura, Ciencias y Artes. (op. cit., pág. 560).

28. Designa 'marcar', 'designar'.

29. En Apolonio, 196 derecho y El Conde Lucanor 256, 12. Citado por Boggs y otros, op. cit., pág. 221.

30. En El Cid, 3604 y Apolonio 363ª . Citado por por Boggs y otros, op. cit., página 221.

31. Del latín doctrina es cultismo. Diccionario Enciclopédico Hispano-Americano de Literatura, Ciencias y Artes, op. cit., página 408.

32. Del latín instruēre. Diccionario Enciclopédico Hispano-Americano de Literatura, Ciencias y Artes, op. cit., pág. 967.

33. Sainz de Robles (op. cit., página 400).

34. Referido en Berceo, San Lorenzo 4 con el término doctrinados. Citado por Boggs y otros, 1946, pág. 200. Se documenta a partir de los siglos XIV y XV: 'E los iovenes nuestros en lur ioventut se adoctrinan con grant treballo de lures personas a las armas', en Fernández, Heredia: Tucídides, 16oㅜ, a; 'En lugar de la adoctrinar, la tomáis más loca', en el Libro de Caballerías, en NBAE, tomo II, 416b; 'con cuya diligencia avemos sido guardados, e con amor sin causar traídos a edad de hombres, e instruidos e adoctrinados en buenas costumbres' Traducción de Mujeres Ilustres. En Boccaccio (1429), ed. RAE (1951, página. 15. Citado por Alonso Pedraz, op. cit., página. 142.

35. Documentado en el Libro del Buen Amor. Citado por Boggs y otros, op. cit., página. 290.

36. Léase en dicha página: ‘...mostrando o dando señales de un camino’.

37. Léase el texto: '..., llevar rectamente una cosa hacia un término o lugar señalado'.

38. Léase el texto: ‘... la intención y las operaciones a determinado fin'. 
39. Se documenta en los siglos XIII y XV como 'producir algo de la nada' y 'dar ser a lo que antes no lo tenía': 'Señor, que crieste las cosas sin otro conseirio' en Berceo, Santo Domingo (c.1230), ed. AE, T. 57, 650; 'La primera es como criar alguna cosa de la que non es, e esta pertenece a Dios tan solamiente', en Alfonso X: Siete Partidos (1256-63), ed. 1807, Part. IV. Tít. XX, Ley 1, t. III, 115. También aparece como 'creo: criar (T1714, E2483)', documentado en Glosario Latín Español (c.1400), ed. 1936, 200b'. En el Libro Exemplos (1400-21), Voc. Etim., s.v.; Tent. Dic. Med., s.v.; Rom, Etim.. wört, 2305: 'Todos somos criados de un Dios e por El nasçcemos'. Y también aparece en Nebrija: Vocabulario español latín (c.1495), s.v. criar, derecho-V, vo , b: 'criar hazer de nuevo, creo, -as, aui'. En el siglo XV, hace referencia a 'nutrir y alimentar la madre y la nodriza al niño con la leche de sus pechos', documentado en Mujeres Ilustres, Boccaccio (1494), ed. RAE, 17, vo , b. En el siglo XII y XV toma la noción de 'alimentar y educar en su casa a un hijo extraño: ' $\mathbf{E}$ otros muchos que crio el Campeador', documentado en el Mío Cid (c. 1140), ed. M. Pidal, IV, Texto 1956, 2514; en los siglos XIII al $\mathrm{XV}$ se acepta como 'instruir, educar y dirigir': 'Los suos sanctos discípulos que él avie criados' en Berceo: San Millán (1235), ed. $\mathrm{AE}, \mathrm{T}$. 57, 310; 'Bien asi como el niño se gobierna e se cria en el cuerpo de la madre fasta que nace' en Alfonso X: Siete Partidos (1256-63). Ed. 1807, Part. II, tít. VII, ley 3, t. II, 45; 'Educare es criar, instituir esoier y mantener' en Alonso de Palencia: Vocab. (1490), 126d. Otras acepciones documentadas son la de 'elegir', 'designar', 'constituir', que se documentan en Juan Manuel: Libro de los Estados (1327-32), ed. AE, t. 51, 357ª y como 'desarrollarse' 'y multiplicarse' en Juan Manuel: Caballeros, 486, 1; 500, 13; 509, 10; Est., 59a 36. En Alonso Pedraz, op. cit., página 813.

\section{Referencias bibliográficas}

Aldea Vaquero, Quintín; Marín Martínez, Tomás y Vives Gatell, José / Instituto Enrique Flores / Consejo Superior de Investigaciones Científicas. Diccionario de Historia Eclesiástica de España II. Madrid: Gráficas Reunidas, S.A. 1972.
Alonso Pedraz, Martín. Diccionario Medieval Español. Desde las Glosas Emilianenses y Silenses (s. X) hasta el siglo XV. Tomos I y II. Salamanca: Universidad Pontifica de Salamanca. 1986.

Álvar Esquerra, Manuel. "Lexicografía". En López Morales, Humberto (Coord). Introducción a la lingüistica actual. Madrid: Gráficas Roanca. 1983.

Álvar y otros. Enciclopedia Lingüística Hispánica II. Madrid: Consejo Superior de Investigaciones Científicas. 1959.

Boggs, R.S. y otros. Tentative Dictionary of Medieval Spanish. Vol. 1. Chapel Hill, North Carolina, USA. 1946.

Casares, Julio. Diccionario Ideológico de la Lengua Española. II edición, 12 tirada. Barcelona: Editorial Gustavo Gili. 1984.

Cejador, Julio y Frauca. Tesoro de la Lengua Castellana. Tomo IX. Vol. 4-9. 1902.

Corominas, Joan. Breve diccionario etimológico de la lengua castellana. III edición muy revisada y mejorada. Diccionarios 2. Madrid: Editorial Gredos S.A. 1967.

Corominas, Joan. Breve diccionario etimológico de la lengua castellana. III edición muy revisada y mejorada. Diccionarios 2. Madrid: Editorial Gredos S.A. 1987.

Corominas, Joan; Pascual, José. Diccionario Crítico Etimológico Castellano e Hispánico. Vol. II. Madrid: Editorial Gredos S.A. 1984.

Cuervo, Rufino José. Diccionario de Construcción y Régimen de la Lengua Castellana. Tomo IV. Santa Fé de Bogotá, 
Colombia: Instituto Caro y Cuervo /OEI. 1992.

De Cobarrubias, Sebastián. Tesoro de la lengua castellana o española. Barcelona: Talleres de S.A. Horta de Impresiones y Ediciones. 1943.

De Miguel, Raymundo. Nuevo Diccionario Latino-Español Etimológico. Madrid: Sáenz de Jubera, Hermanos Editores. 1914.

Diccionario de uso del español actual. Madrid: Ediciones S.M. 1996.

Diccionario Enciclopédico Hispano-Americano de Literatura, Ciencias y Artes. Tomo octavo. Barcelona: Montaner y Simón, Editores. 1981.

Dizionario Enciclopedico Di Pedagogia. Vol. II. (S.f.) Torino: Editorial S.A.J.E.

Enciclopedia Vniversal Ilvstrada Evropea -Americana. Tomo XXIV. Barcelona: Hijos de J. Espasa, Editores.

Ferrater Mora, José. Diccionario de Filosofía. Madrid: Alianza Editorial. 1980.

Foulquié, Paul. Diccionario de Pedagogía. Barcelona: Oikostan, S.A.-Ediciones. 1976.

García Carrasco, Joaquín. 'Formación'. En Fe cristiana y sociedad moderna. 8. Edición española dirigida por Alfonso Álvarez Bolado y otros. España: Ediciones S. M. 1985.

García Carrasco, Joaquín; Del Dujo, Ángel. Teoría de la Educación. Salamanca, España: Ediciones Universidad de Salamanca. 1996.
García Hoz, Víctor. Diccionario de Pedagogía Labor. Tomo I. Barcelona: Editorial Labor, S.A. 1870.

Honore. Para una teoría de la formación. Madrid: Narcea, S.A. de Ediciones. 1980.

Laeng, Mauro. Vocabulario de Pedagogía. Barcelona: Editorial Herder. 1979.

Merani, Alberto. Diccionario de Pedagogía. Barcelona: Grijalbo. 1983.

Nebrija, Elio Antonio. Dictionarium ex hispaniense in latinum sermonen. (s.f.)

Pellicia, Guerrino; Rocca, Giancarlo. Dizionario Degli Instituto Di Perdezzione. Vol. IV. Roma: Edizione Paocine. 1977.

Real Academia Española. Diccionario de la Lengua Española. Madrid: Editorial Espasa Calpe, S.A. 1970.

Real Academia Española. Diccionario de la Lengua Española. Tomos I y II. 20 edición. Madrid: Editorial Espasa Calpe. 1984.

Saglio, Edmond. Dictionarie Des Antiqués Grecques et Romaines. París: Librarie Hachette. (s.f.)

Sainz de Robles, Federico. Ensayo de un diccionario español de sinónimos y antónimos. 8 edición. 2 reimpresión. Madrid: Aguilar, S. A.1971.

Trucco, Giovanni. Grande Dizionario Enciclopedico. Torino: Unione Tipografico-Editrice Torinese. 1935.

Trujillo, Ramón. El campo semántico de la valoración intelectual en español. La Laguna. 1970.

Trujillo, Ramón. Principios de semántica textual. Madrid: Editorial Arco Libros, S.L. 1996. 